\title{
Communicating About Groundwater Depletion
}

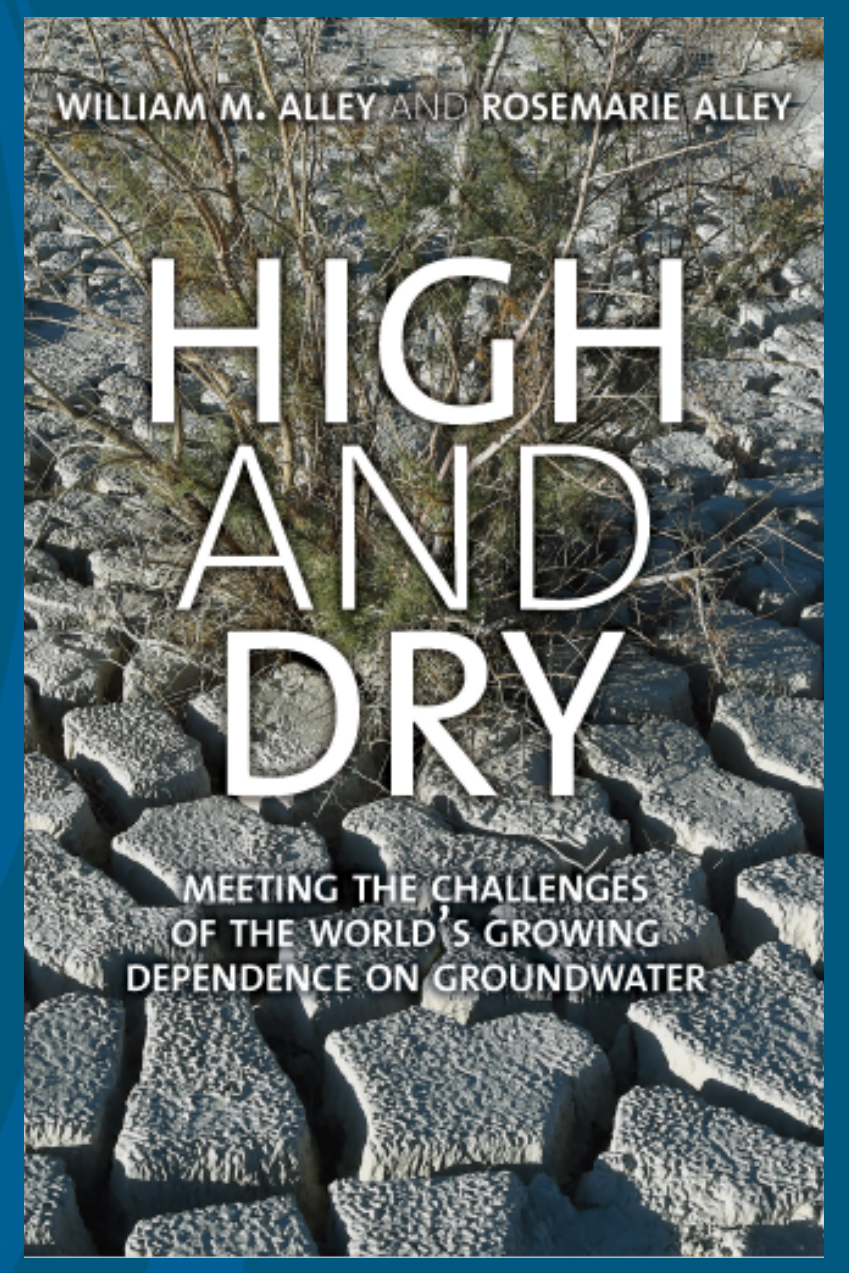

\author{
William M. Alley \\ Director, Science and Technology \\ National Ground Water Association \\ GSA North-Central Annual Meeting \\ Ames, lowa \\ April 17, 2018
}




\section{Global groundwater depletion}

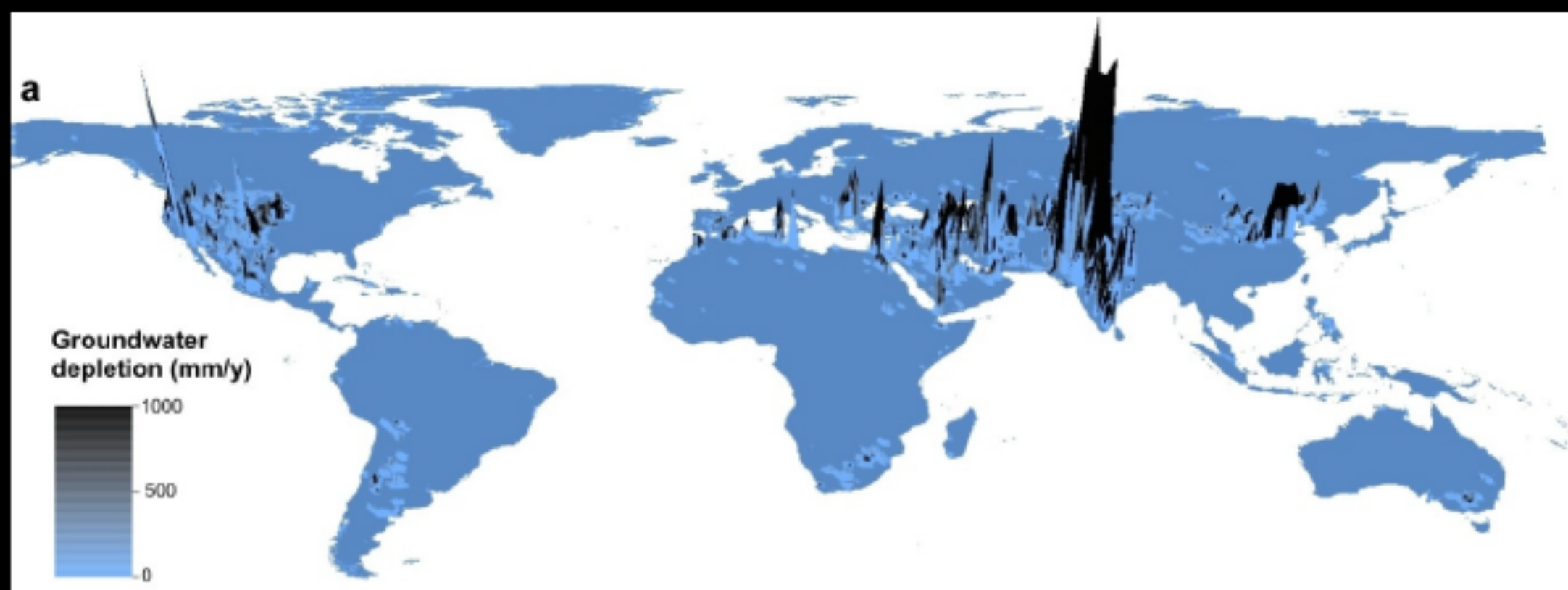

Wada et al (2009) remapped by Aeschbach-Hertig and Gleeson (2012) 


\section{Five countries account for $60 \%$ of the world's groundwater use}

- India (25\%)

- United States (11\%)

- China (11\%)

- Pakistan (7\%)

-Iran (6\%) 


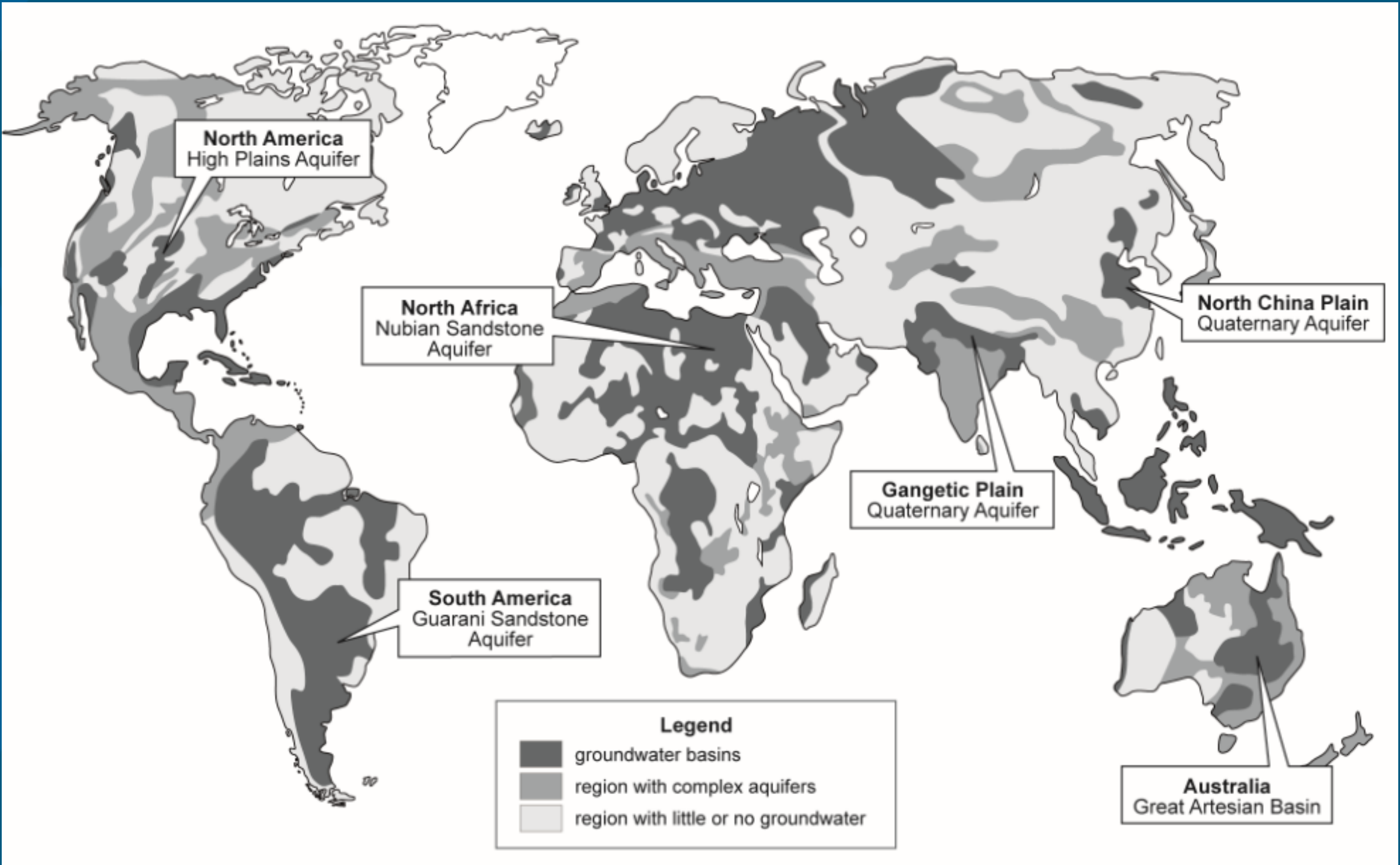

Foster and Chilton (2003) 


\section{“Houston, we have a problem," Apollo 13}

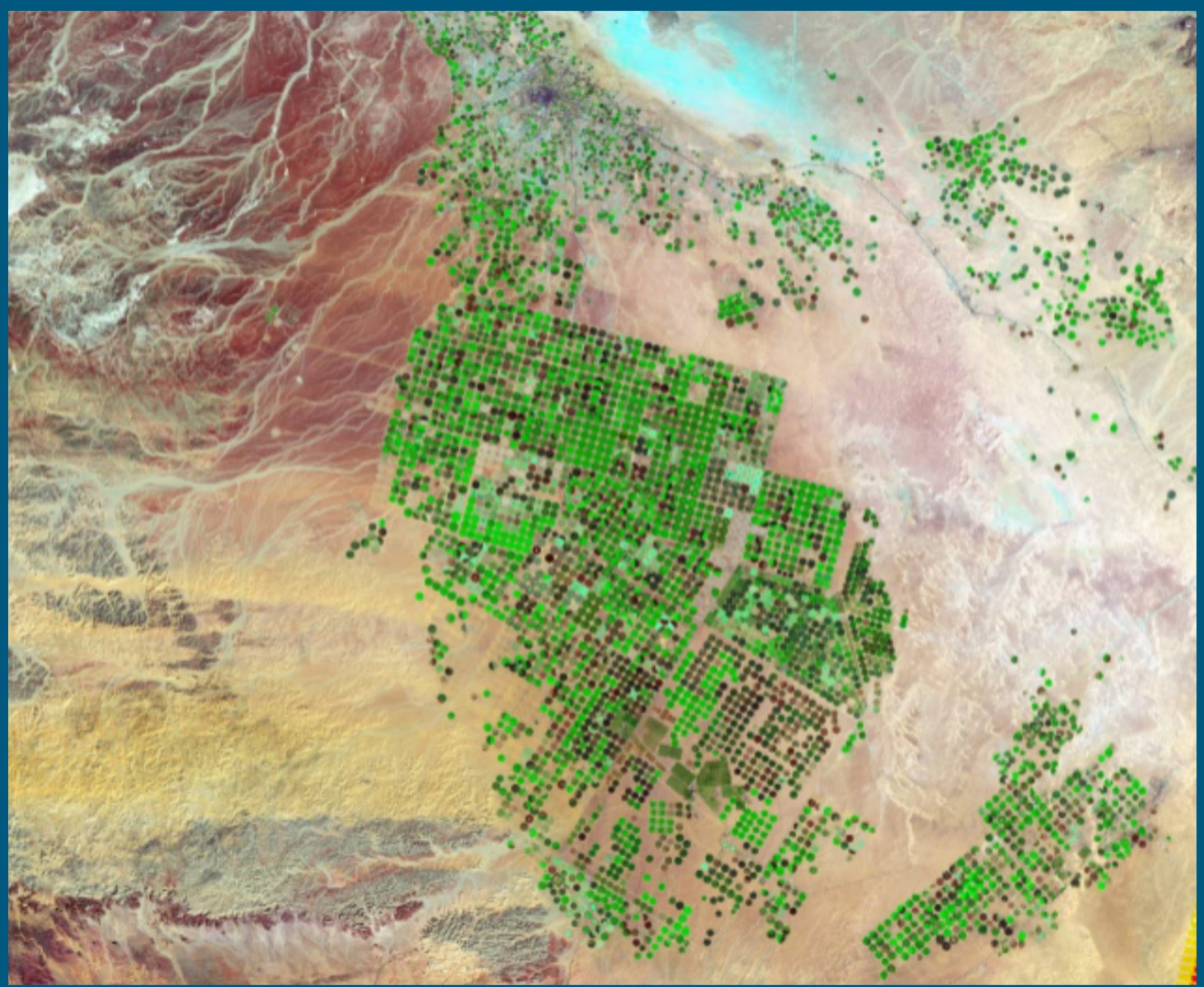

NASA photo 


\section{Northwest India: Groundwater Depletion from GRACE}

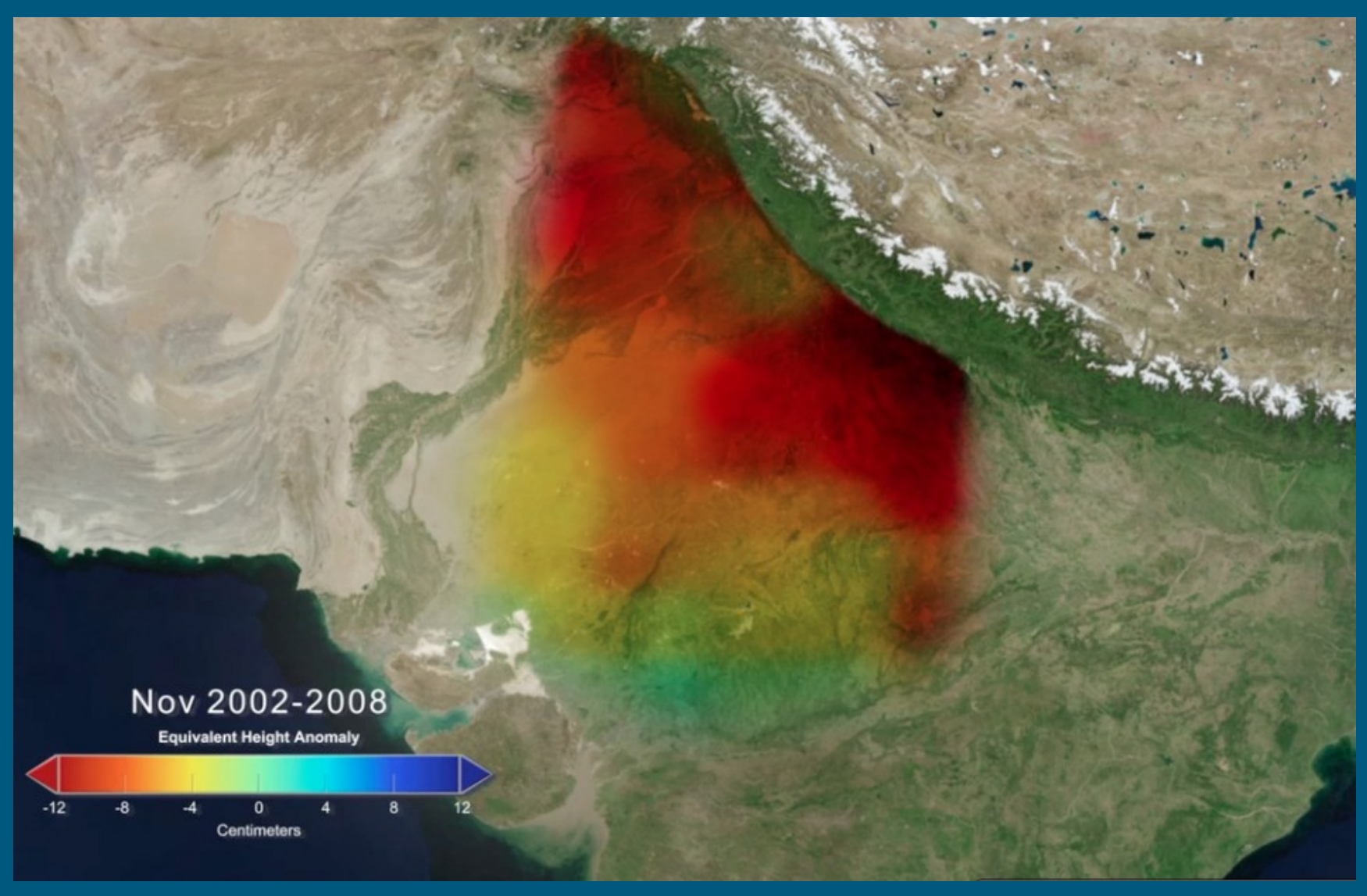

Rodell et al (2009) Nature 


\section{Main Hydrogeological Provinces of India}

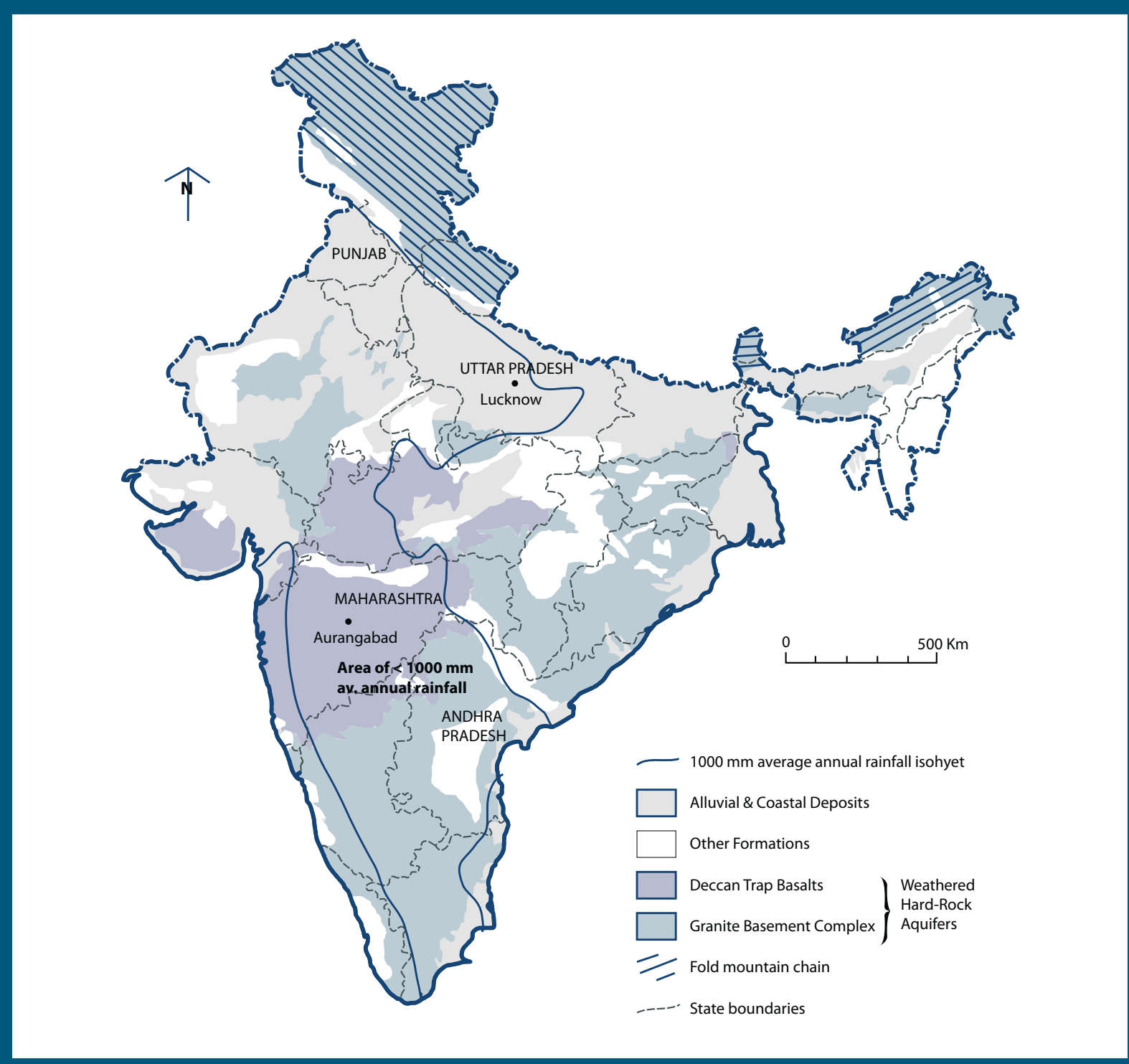

NGWA 


\section{Arsenic in Groundwater}

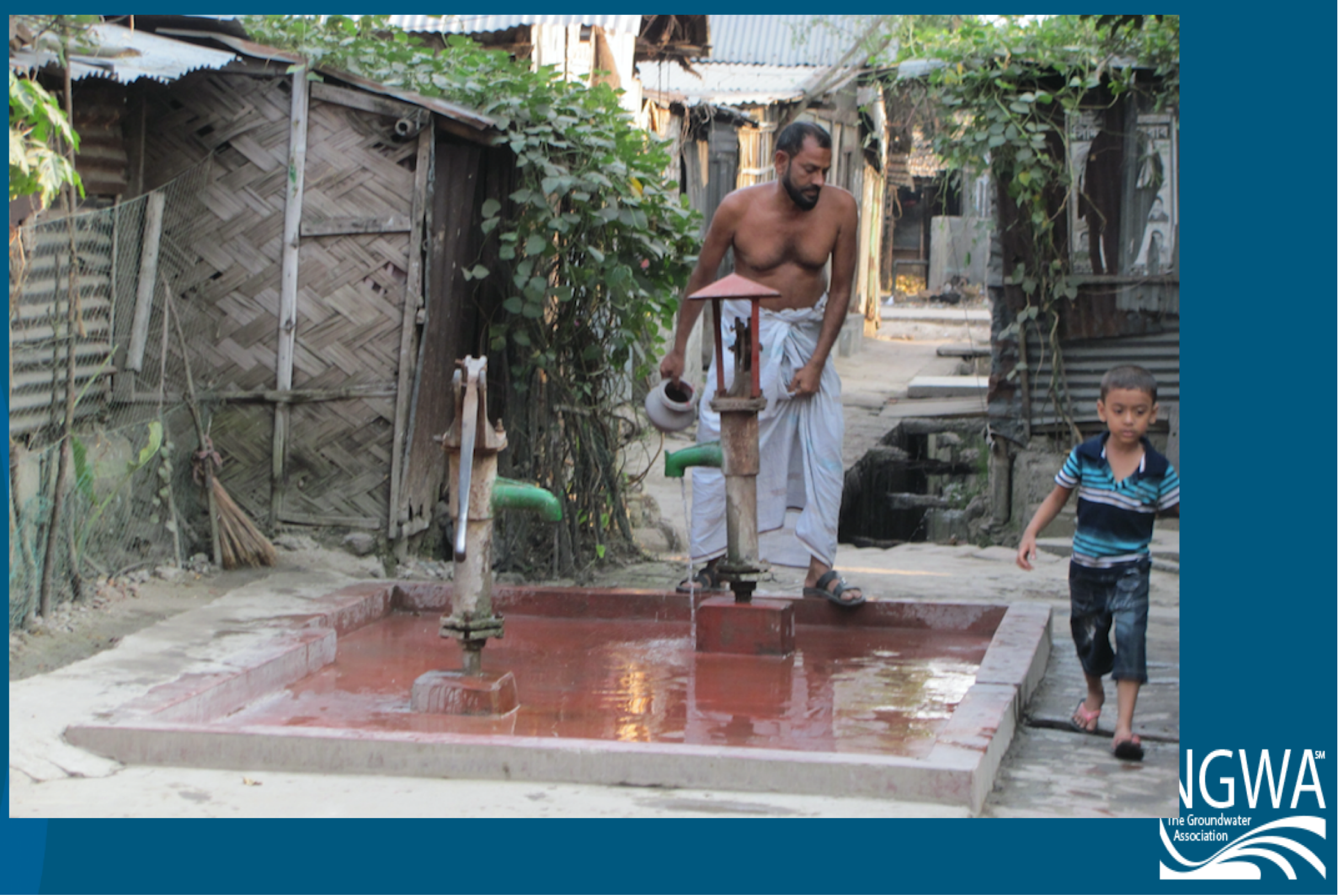


The greatest shortcoming of groundwater governance has been called "its failure to grasp the central importance of the human dimension ... and the consequent neglect of stakeholders in governance and management."

Global Environment Facility et al. 2016 


\section{Bangkok, Thailand}

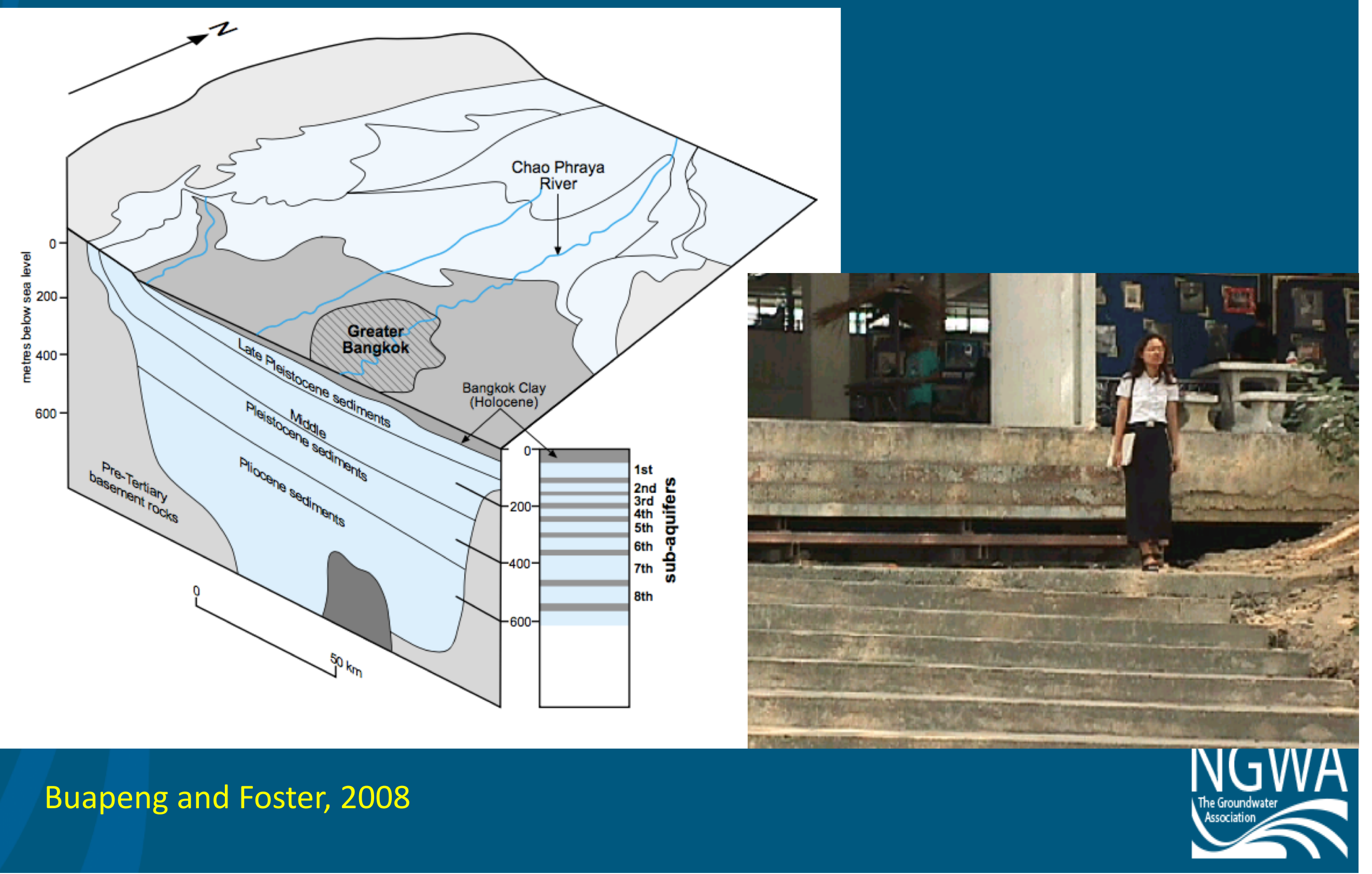




\section{Bangkok, Thailand}

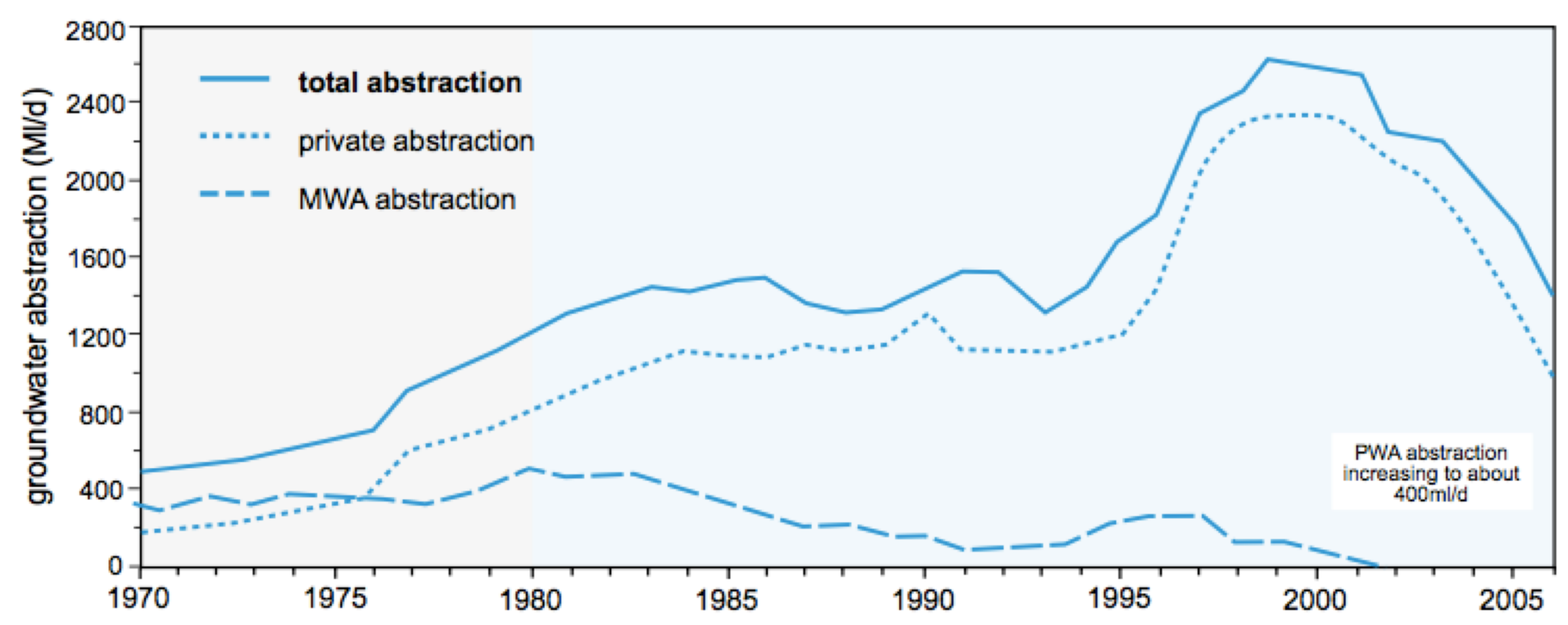

Buapeng and Foster, 2008

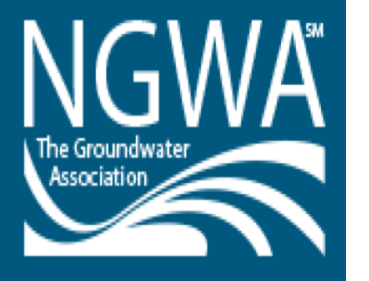




\section{Denmark: Aquifer Protection}
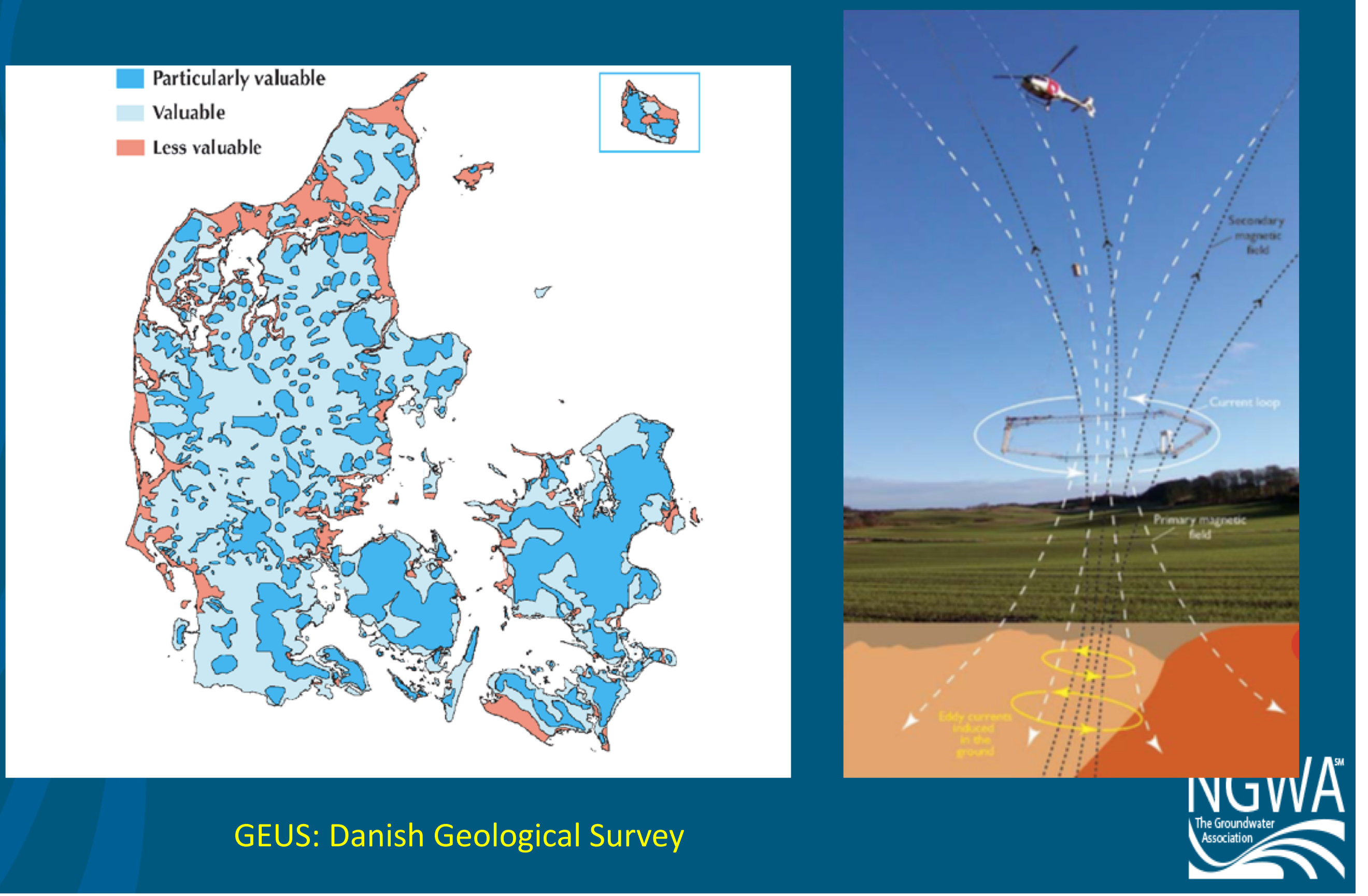

GEUS: Danish Geological Survey 
Collaborative Modeling and Citizen ScientistsSan Pedro River, AZ
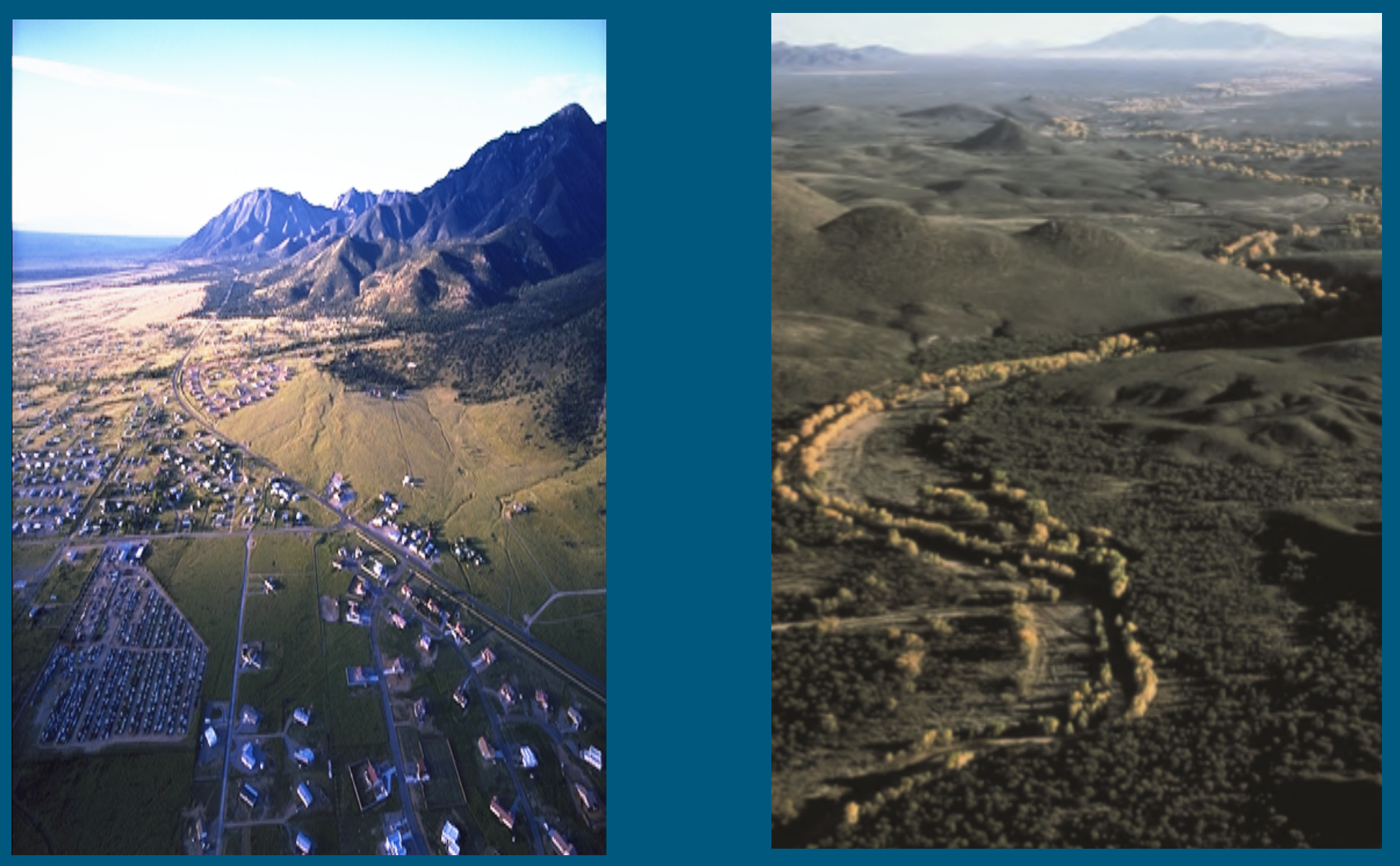

NGWA 


\section{Depletion of a small part of the total volume of groundwater}

can have large effects on surface water, water quality, or subsidence which become limiting factors to development

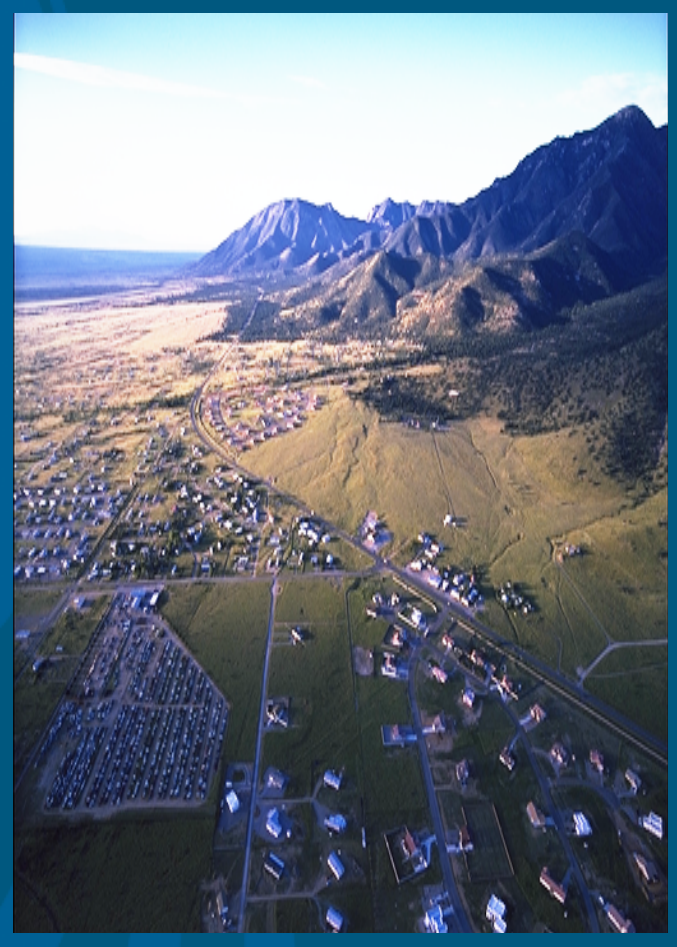

Upper San Pedro Basin, $\mathbf{A Z}$

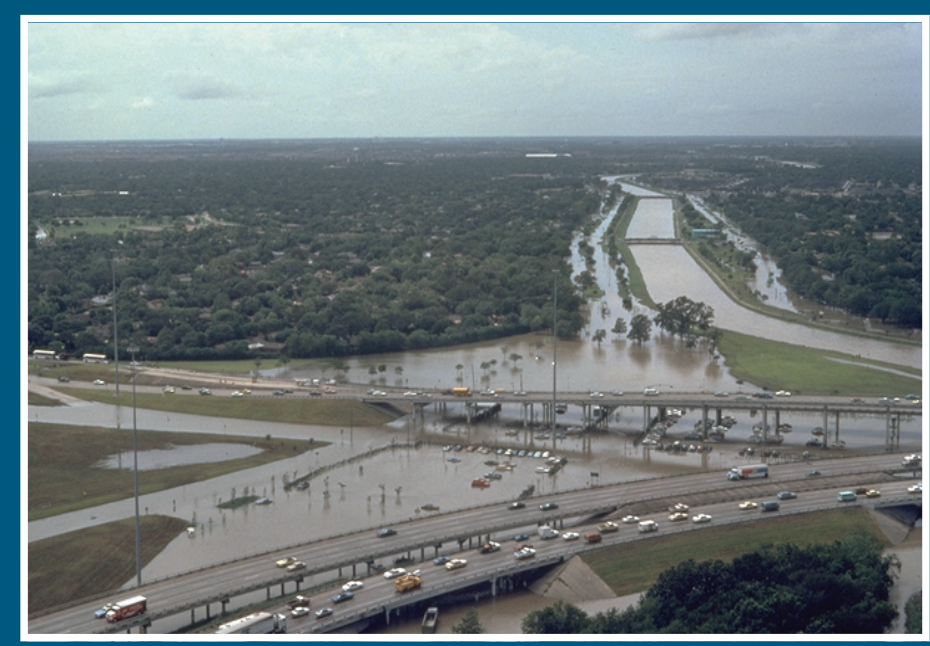

Houston, TX

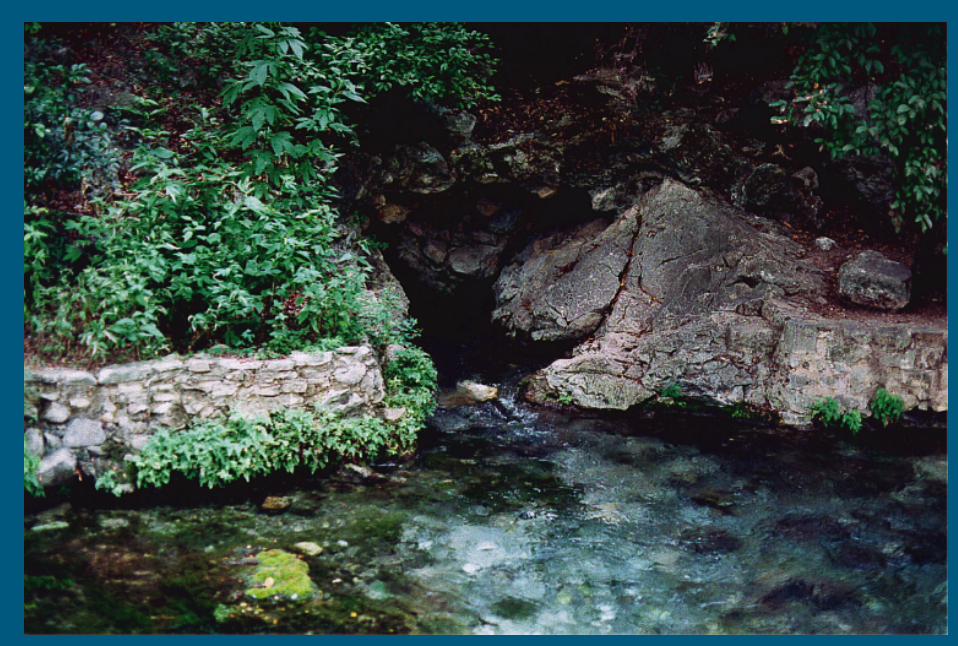

Edwards Aquifer, TX

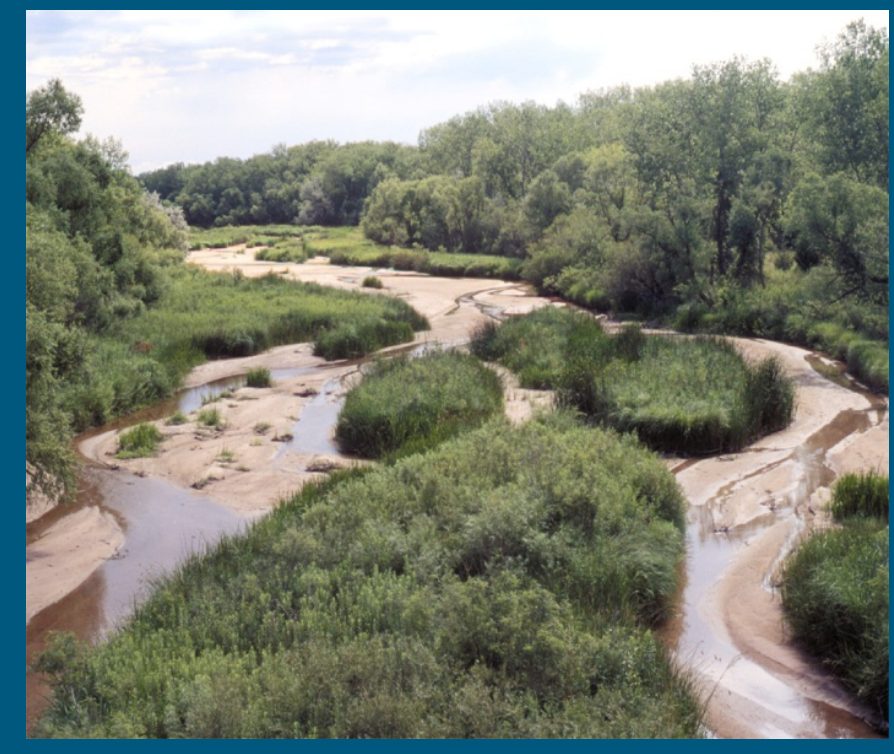

Republican River Basin, $\mathrm{CO}, \mathrm{KS}, \mathrm{NE}$

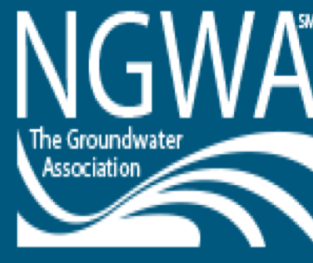




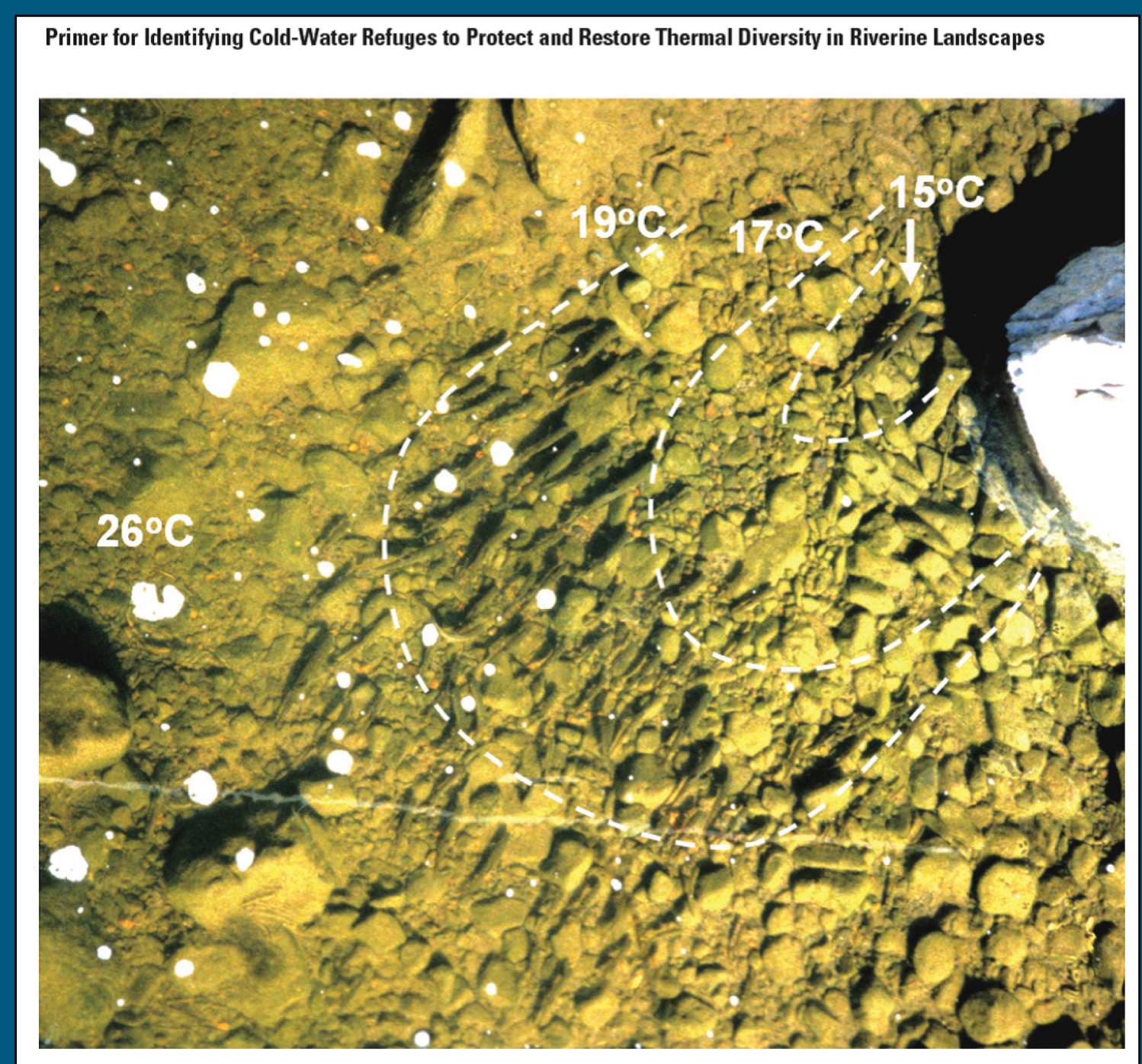

Figure 2.4.1.2. Rainbow trout in Joseph Creek in northeastern Oregon exhibit size hierarchy in occupying a cold-water refuge, with the largest individual in the coldest thermal zone (see Ebersole and others, 2001). When the availability and size of cold-water areas is limited, fish may elect habitats that are less desirable for growth and disease resistance (i.e., through crowding) in order to minimize deleterious physiological effects of high water temperature. Photograph taken by J. Ebersole in 1994.

Torgersen, C.E., Ebersole, J.L., Keenan, D.M., 2012, Primer for Identifying Cold-Water Refuges to Protect and Restore Thermal Diversity in Riverine Landscapes: EPA 910-C-12-001

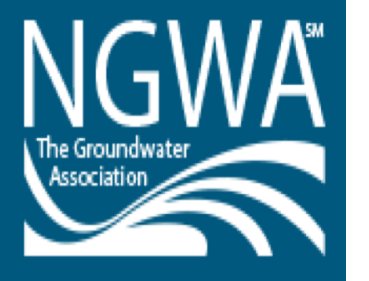




\section{Human vs Hydrologic Time Scales}

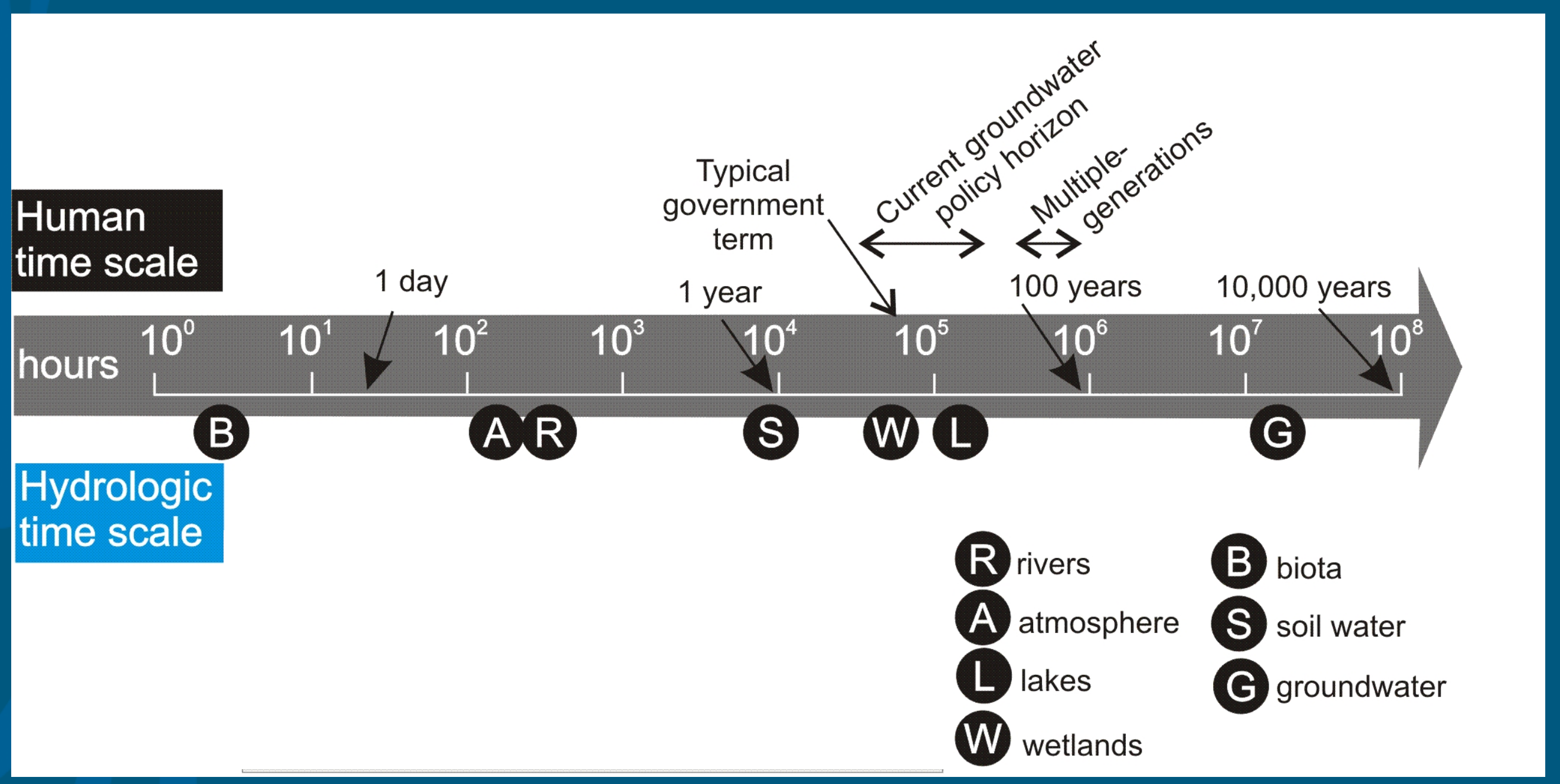

Gleeson et al. (2012) 


\section{Streamflow Capture: Arizona}
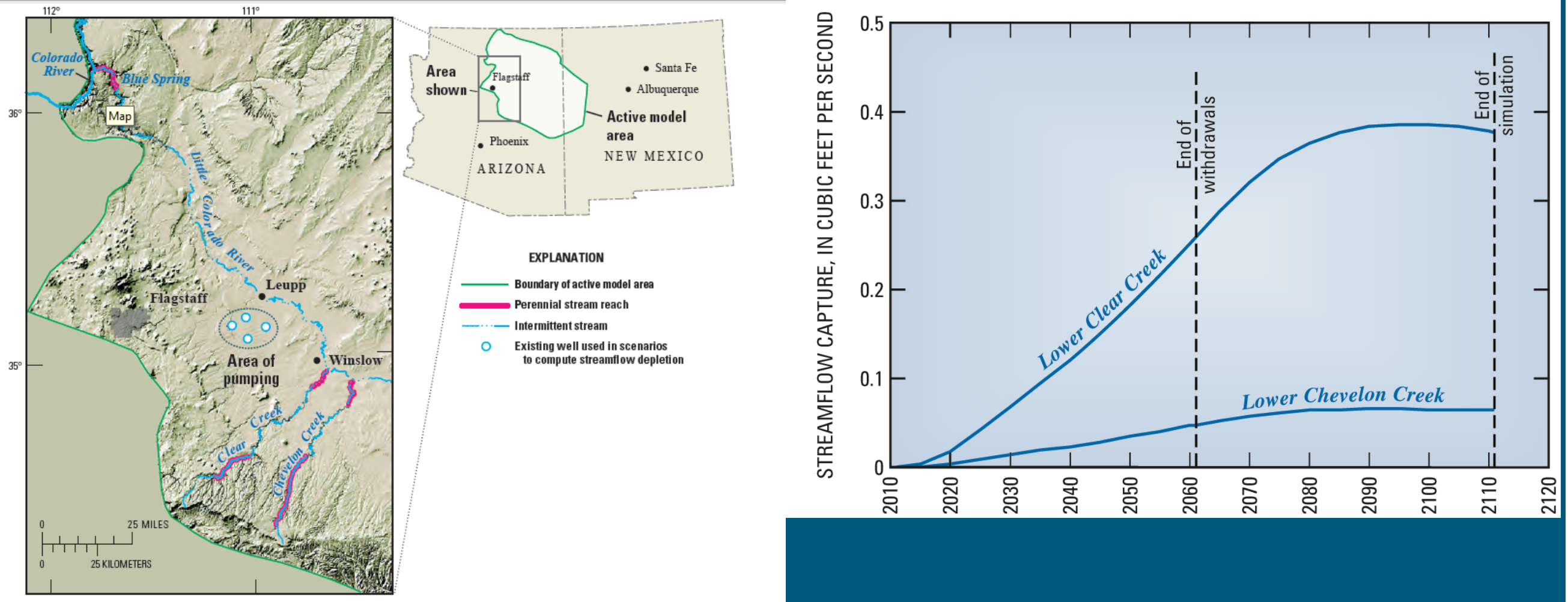

Base from U.S. Geological Survey digital data,
1.100,000, 1980, Lambert Conformal Conic project

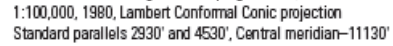

Leake, Hoffmann, and Dickinson, 2005

NGWA

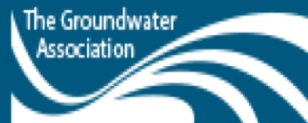




\section{How resilient is groundwater?}

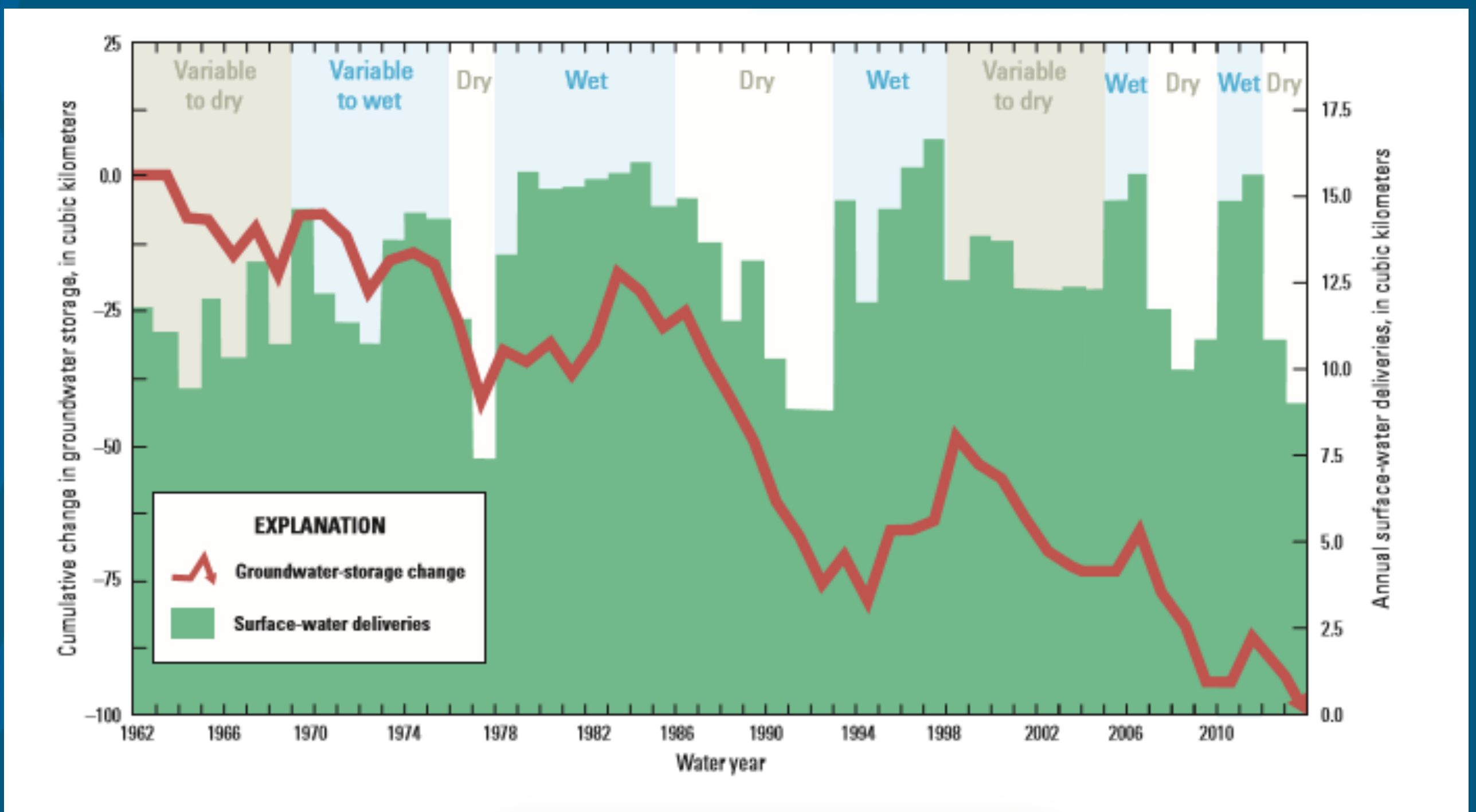

USGS Fact Sheet 2015-3084 


\section{Drought-proofing Groundwater}

- Analyze GW systems for their resilience and vulnerability to climate perturbations rather than just assuming groundwater is a convenient backup supply

- Raise awareness about maintaining groundwater as a reserve

--Monitoring water use and water levels

--Potential for managed aquifer recharge

-Work toward laws, regulations, and incentives that encourage use of surface water during wet periods and prepare for increased groundwater use during droughts 


\section{Factors Contributing to Good Groundwater Governance}

- Recognizing surface water and groundwater as a single resource

- Active engagement of local stakeholders in the decision-making process

- Pressure from external bodies to achieve suitable and workable solutions

- Public education on groundwater and its importance

- An emphasis on public guardianship and collective responsibility

- Integration of GW considerations into other policies (agriculture, energy, etc.) 


\section{Factors Contributing to Good Groundwater Governance (cont.)}

- Adequate laws and enforcement

- Adequately funded and properly staffed groundwater management agencies

- Characterization of major aquifer systems

- Effective monitoring of groundwater status and trends by an independent agency

- Recognizing the long-term response of groundwater systems

- Recognizing the feedbacks between groundwater and climate

- Community leadership 


\section{Questions?}

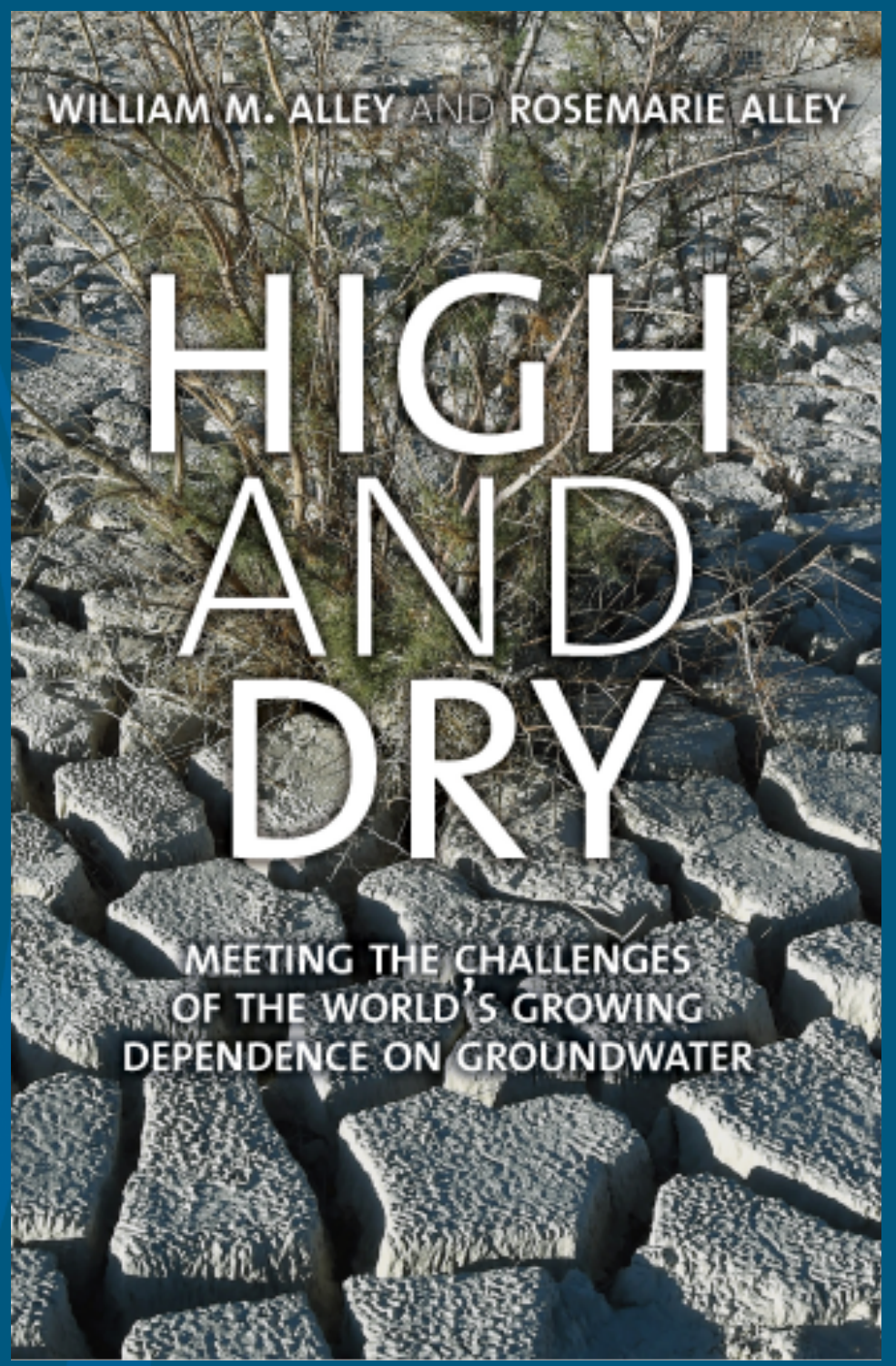

"Imagine a book about groundwater that reads like a novel, and is overflowing with interesting and essential knowledge about a much-neglected topic. This is the book."

Bruce Babbitt, former US Secretary of the Interior (and AZ Governor)

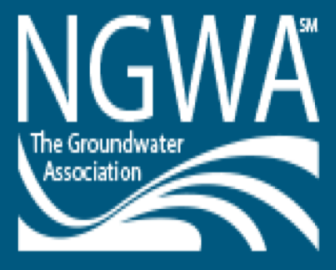

